\title{
Research report \\ Effects of an electrolytic lesion of the prelimbic area on anxiety-related and cognitive tasks in the rat
}

\author{
Hans Maaswinkel *, Willem-Hendrik Gispen, Berry M. Spruijt \\ Rudolf Magnus Institute for Neurosciences, Department of Medical Pharmacology, Utrecht University, PO Box 80040, 3508 TA \\ Utrecht, The Netherlands
}

Received 18 July 1995; revised 28 November 1995; accepted 28 November 1995

\begin{abstract}
The aim of this paper was to study the role of the prelimbic area of rats in response selection. A bilateral electrolytic lesion was made in the prelimbic area. The rats were tested in the Morris water-maze, the conditioned shock-prod burying test, the elevated plus-maze, a modified open field test, and the step-through passive avoidance test. In the water-maze during initial acquisition, the latency times of the lesioned rats were not different from those of the controls, but they found the platform faster than the shamoperated rats after the platform was placed in a new position. The lesion did not affect performance in the shock-prod burying test. In the elevated plus-maze the lesioned rats were more active than the sham-operated rats and spent more time on the open arms. In the open field there was no difference between lesioned and sham-operated rats with regard to distance travelled or the time spent near the object in the center of the open field. In the passive avoidance test the lesioned rats had a shorter latency time to enter the shock compartment during the retention trial than the sham-operated rats did. The results were discussed in relation to those of similar studies. The extent and precise localisation of the lesion seems to be crucial for the outcome: lesions confined to the prelimbic area may have the opposite effects of larger lesions. Furthermore, it may well be that the prelimbic area is only involved in processing of stimuli of a specific sensory modality, as made probable by the results of different conditioned reinforcement tasks. Finally, it was stated that we still lack a hypothesis about the precise role of the prelimbic area in response selections.
\end{abstract}

Keywords: Prelimbic area; Elevated plus-maze; Passive avoidance: Shock-prod burying test: Open field; Anxiety; Response selection

\section{Introduction}

The prelimbic area of the prefrontal cortex (Brodman area 32) of the rat is part of an anatomical network. involving among others mediodorsal thalamus. entorhinal cortex, basolateral amygdala, ventral striatum. ventral pallidum, and piriform cortex [21]. Many of these areas play direct or indirect roles in goal-directed behavior or executive functions $[13,16,19.29,30]$. However, the anatomical connections of the rodent prelimbic area are very different from those of the primate dorsolateral prefrontal cortex, which is according to Kolb [26] a homologue structure to the rodent medial prefrontal cortex (including the prelimbic area) and which is seen as the executive center of the primate

\footnotetext{
* Corresponding author. Fax: (31) (30) 2539032:

e-mail: B.M.Spruijt@med.ruu.nl
}

brain $[14,15,44]$. For instance, unlike the primate dorsolateral prefrontal cortex it receives afferent projections from the hippocampus and not from the parietal cortex [2.8.37]. The rodent prelimbic area projects to many brain areas involved in autonomic and innate motor functions, such as lateral hypothalamus, central gray, nucleus tractus solitarii, locus coeruleus $[34,35,43,45,46,50]$.

According to this anatomical position, the rodent prelimbic area has repeatedly been assumed to play a role in response selection. According to Powell et al. [42] this area is involved in autonomic conditioned responses, such as conditioned bradycardia. Similarly, Terreberry and Neafsey [50] call the medial prefrontal cortex a visceral motor region. According to another view [31] it may have the function "to update appropriate response outputs dependent on ... [the] internal state", which may among others be determined by the 
amygdala, which determines the 'emotional significance' of stimuli. Related to this is the opinion that the medial prefrontal cortex plays a role in stress responses [4], namely in finding appropriate coping reactions [9]. Besides these hypotheses, there are also those assigning to the prelimbic area a function in selecting responses in a working memory task context [18] or selecting 'cognitive strategies' [5]. All of these views seem to assume that the prelimbic area has a subservient role to other brain regions involved in executive or cognitive functions. According to Poucet [41], the investigation of the spatial configuration of objects is not dependent on the prelimbic area, but the identification of a particular object on a specific location is. Both configuration and identification, however, are dependent on an intact septum. In the same way, an intact hippocampus is required for acquisition of the Morris maze task (learning the position of a hidden platform in a water pool) and for the 'reversal' task (learning the position of the platform in a new position) $[32,33]$. However, the medial prefrontal cortex is only required for the reversal task and thus obviously not involved in the spatial task [10]. Brito and Brito [5] even assume that "there seems to be a hierarchy such that the septohippocampal system plays a larger role than the prelimbic cortex".

Although the scope of response selections carried out by the prelimbic area is far from clear yet, there are some indications for a constraint to single autonomic or motor actions or inhibitions (like freezing or bradycardia). In a series of studies carried out by Holson and Walker [23-25] a lesion of this area led to altered foodhoarding, burrowing, exploration, and social behavior, but only under frightening conditions (novelty, high illumination). According to Holson [23-25] the lesion produced an increase of timidity. This concerns emotionality. This view is closely related to the one by Morgan and LeDoux [31] (as mentioned earlier). Expressed in terms of responses, increased timidity may reduce the time spent on social behavior or burrowing, perhaps by elevation of freezing [31]. The point is that also according to Holson [23-25]. the prelimbic area does not control sequencing of activities in complex innate behavior (such as burrowing or self-grooming, which may be ruled by a "natural syntax' [3]). switching between behaviors in an environment-dependent manner (such as may be the case in food-hoarding and exploratory activities), or "associating stimuli in their spatial and temporal context" [49] (which may be important for acquisition of the Morris maze task [52] and reacting to altered spatial configurations [17]-both functions are not influenced by a lesion of the prelimbic area $[10,41])$. These remarks are important because the suggestion made by Kolb [26] more then ten years ago that the medial prefrontal cortex (Brodman areas 24, 32 , and 25 ) in the rat could be a structure homologue to the primate dorsolateral prefrontal cortex-although to our current knowledge anatomically unlikely [8] and behaviorally never evidenced (at least as far as areas 32 and 25 are concerned) - is still being forwarded in recent literature. There is therefore a stark tendency to overinterpret behavioral results of lesion studies concerning this area. De Bruin et al. [10] for instance compare the slight impairment of rats with a lesion of the medial prefrontal cortex in the 'reversal' task in the Morris maze with difficulties of patients with frontal lesions in the Wisconsin Card Sorting Test. There are, however, two problems with such an explanation. Firstly, there is reason to believe that the difficulty of patients with the sorting tests is due to impaired extra-dimensional set shifting [36], whereas perseveration in rats could have a totally different cause, see for instance the 'reward modulation hypothesis' [11]. Secondly, why is it that (to our knowledge) nobody has ever made the connection between the much more severe perseveration after hippocampal lesion and the sorting test? Probably because humans with such a lesion are not disturbed in the sorting test. There are thus two possibilities: either perseveration is not a good model for deficiencies with the Wisconsin Card Sorting Test or there are important neuropsychological species differences between rats and humans.

In this study we investigated the effects of a bilateral electrolytic lesion of the prelimbic area in a battery of five neuropsychological tests which are sensitive to lesions of other parts of the executive anatomical network to which the prelimbic area belongs [21]. The purpose was to further narrow down the sorts of response selection [41] this area is involved in. The tests chosen were: Morris maze test (already studied by De Bruin et al. [10], but they obtained different results than Kolb et al. [27]), elevated plus-maze, passive avoidance, open field test, and shock-prod burying test.

\section{Methods}

\subsection{Subjects}

Thirty-one male Wistar rats (animal facility University of Utrecht) were used and weighed about $350-430 \mathrm{~g}$ at the time of operation. For the passive avoidance test 8 lesioned and 8 sham-operated rats were used; for the other four tests 8 lesioned and 7 sham-operated rats. The experiments started about 3 weeks after the operation. The rats were housed in Macrolon cages in groups of two or three. The lighting conditions were reversed: 8.00 p.m. -8.00 a.m. white light, 8.00 a.m. -8.00 p.m. red light. All experiments were performed between 10.00 a.m. and 17.00 p.m. Water and food were available ad libitum. The rats were allowed to recover for three weeks before the experiments were started. 


\subsection{Surgery}

The rats were anesthetized with $0.05 \mathrm{ml} / 100 \mathrm{~g}$ i.m. Hypnorm (containing $0.315 \mathrm{mg} / \mathrm{ml}$ fentanyl citrate and $10 \mathrm{mg} / \mathrm{ml}$ fluanisone) and muscle relaxation was obtained with $0.1 \mathrm{ml} / 100 \mathrm{~g}$ s.c. Dormicum (midazolamhydrochloride). The electrode was inserted through a hole in the scull and lowered vertically to a position $\pm 0.6 \mathrm{~mm}$ lateral, $3.2 \mathrm{~mm}$ anterior to the bregma and $4.2 \mathrm{~mm}$ ventral from the top of the skull (according to the stereotactic atlas of Paxinos and Watson [38]). Then a thermolesion was made, applying an electric current resulting in a temperature of $70^{\circ} \mathrm{C}$ for $60 \mathrm{~s}$.

\subsection{Apparatus}

The Morris maze consisted of a black swimming pool, $210 \mathrm{~cm}$ in diameter and $35 \mathrm{~cm}$ deep. A black cylindric platform $(8 \mathrm{~cm}$ diameter) was placed $50 \mathrm{~cm}$ from the rim. In its second position it was moved $180^{\circ}$. The pool was filled with water (average temperature $26^{\circ} \mathrm{C}$ ) until the platform was about $2 \mathrm{~cm}$ under the water level. A video-computer system (Noldus Information Technolgy, Wageningen, The Netherlands) [47] was used to track the movements of the rat. The room was illuminated with red light.

The open field with object consisted of a circular arena with a diameter of $140 \mathrm{~cm}$ and a height of $35 \mathrm{~cm}$. It was placed in a $200 \times 200 \mathrm{~cm}$ sound-proofed and ventilated room, which was illuminated by a white fluorescent strip light. A cylindric metal object $(16.5 \mathrm{~cm}$ high, $8 \mathrm{~cm}$ in diameter) was placed in the center of the open field. The movements of the rat were registered with a video-computer system. The total distance travelled and the time spent within a radius of $20 \mathrm{~cm}$ from the object (central) were calculated. The change in the time spent in the central zone was assessed by calculating this time over five blocks of $2 \mathrm{~min}$.

The elevated plus-maze consisted of a wooden apparatus with a central $30 \times 30 \mathrm{~cm}$ platform (approx. $70 \mathrm{~cm}$ above the floor), two $40 \times 10 \mathrm{~cm}$ open arms, and two $40 \times 10 \times 22.5 \mathrm{~cm}$ closed arms. A 40 -watt lamp was suspended about $25 \mathrm{~cm}$ above the central platform. The experimental room itself was illuminated by red light.

The shock-prod burying test was carried out in a $61 \times 25 \times 35 \mathrm{~cm}$ transparent box with one opening for the wired prod on one of the shorter sides. A thick layer of sawdust (approx. $3 \mathrm{~cm}$ ) was spread over the floor. The behaviors of this and previous tests were scored with an observation program (BEHAVIOR). The room was illuminated with red light.

The passive avoidance test was of the step-through type [1]. It consisted of a dark compartment with a electrifiable grid on the floor. At one side there was an entrance with a sliding door. In front of it there was a rectangular platform, above which a white light $(40$ watt) was suspended.

\subsection{Procedures}

Morris maze. In each trial the rat was placed, with its head facing the rim, into the water at one of four starting points. The starting point was chosen in a random fashion. Each trial lasted until the rats climbed onto the platform and remained there for $10 \mathrm{~s}$, but with a maximum of $2 \mathrm{~min}$. If the rat did not reach the platform within this period, it was placed on the platform for 10 s. On the first 3 days the rats received four trials a day, on day 4 and day 5 six trials. On day 6 two trials were given. Then the platform was placed in a new position and four more trials given. The intertrial interval was about $15 \mathrm{~min}$.

Open field with object. At least $1 \mathrm{~h}$ before the start of the experiment the rats were brought to an adjacent room, which was illuminated with red light. The observation period lasted $10 \mathrm{~min}$. Between sessions the floor of the open field was cleaned with water. This paradigm was introduced by Spruijt et al. [48].

Elevated plus-maze. The experimental animals were brought to the experimental room at least $1 \mathrm{~h}$ before the experiment started. At the beginning of the 5-min session a rat was placed on the central platform and the observation program was started. Each entry onto one of the four arms or onto the central platform was scored only if all four legs were placed in that new position.

Shock-prod burying test. The test was performed in the same room the rats were housed in. The rats were placed in the apparatus and $3 \mathrm{~min}$ later the electrified prod $(2 \mathrm{~mA})$ was inserted. The observation period started when the rat touched the prod for the first time and lasted for $10 \mathrm{~min}$. The following parameters were calculated: number of shocks and time spent burying, freezing, and exploring. After each session the sawdust was renewed.

Passive avoidance. On the first day the rats were placed for $2 \mathrm{~min}$ in the dark compartment with the door closed. Immediately afterwards they were placed on the platform with their heads away from the door. After they had entered the dark compartment, the door was shut and the rats were left in it for about $10 \mathrm{~s}$. On the second day they received a second habituation trial, but this time they were immediately placed on the platform. Three hours later they received the shock trial. They were again placed on the platform and after they entered the dark compartment, the door was closed and they received an electric shock ( $0.4 \mathrm{~mA}$ for $2 \mathrm{~s})$. The retention trial was given $24 \mathrm{~h}$ later. The step-through latency was measured, with a maximum of $300 \mathrm{~s}$.

The same rats were used for the first four tests in the following sequence: Morris maze, 2 weeks later open field, the next day elevated plus-maze, and 5 days later the shock-prod burying test. The step-through passive 
avoidance test was carried out with another group of rats.

\subsection{Histology}

The rats were killed with an overdose of pentobarbital. The brains were removed and kept in a solution of $4 \%$ formaldehyde. Slices $(35 \mu \mathrm{m})$ were made and stained with thionine. The lesion was rather small and mostly confined within the borders of the prelimbic area. In some cases small sections of the anterior cingulate cortex or the infralimbic area were affected. See Fig. 1.

\subsection{Statistics}

ANOVA with repeated measurements was applied for the acquisition trials and for the reversal trials in the Morris maze test and for the open field test, a simple ANOVA for the other tests.

\section{Results}

\subsection{Morris maze}

For the single trials before the platform was moved (see Fig. 2) the ANOVA with repeated measurements

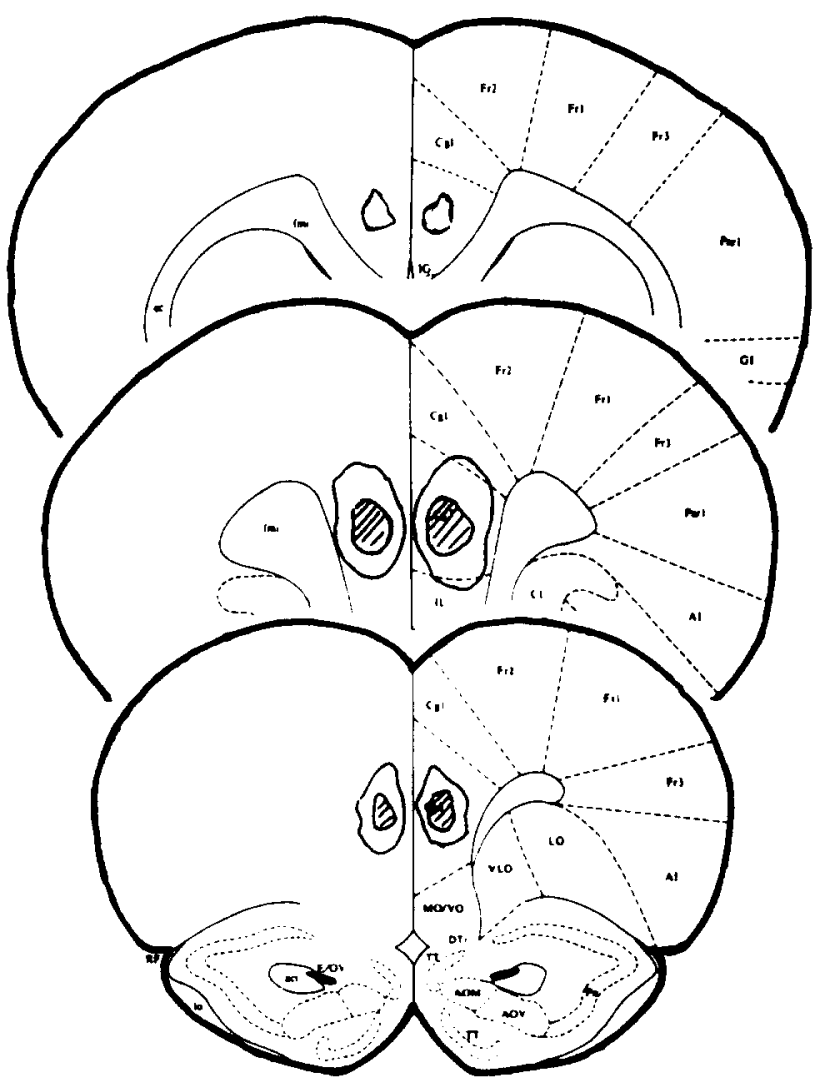

Fig. 1. The electrolytic lesion of the prelimbic area. The hatched area represents the smallest lesion. the blank the largest lesion. Adapted from Paxinos and Watson [38]

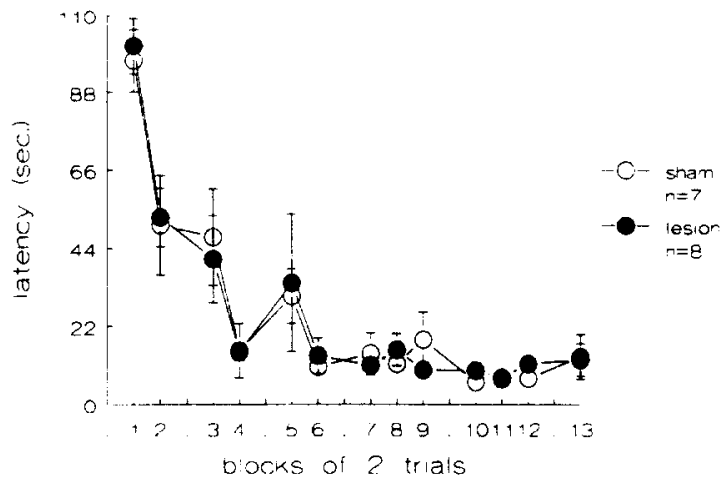

Fig. 2. Morris maze. Mean ( \pm S.E.M.) latency times of the sham-operated and the prelimbic-lesioned rats presented as blocks of two consecutive trials before the platform was moved.

showed no significant difference between the groups. Only the overall time effect was significant with $F(25,325)=17.83$ and $P<0.001$. The interaction group $\times$ time effect was not significant. After the platform was moved (Fig. 3) there was a significant overall time effect with $F(3,39)=16.93$ and $P<0.001$, and a significant group $\times$ time interaction effect with $F(3,39)=3.1$ and $P<0.05$, whereby the lesioned animals appeared to learn the new position of the platform quicker than the sham-operated rats. In the single trials there was no difference between the groups in the time taken to find the platform, as assessed by a $t$-test.

\subsection{Open field with object}

There was no difference in distance travelled between the groups. The overall time spent in the central area, analyzed in order to evaluate object-directed behavior, near the object was also not different. The ANOVA with repeated measurements over the five blocks of $2 \mathrm{~min}$, to assess whether the lesioned rats were disinhibited from entering the central area, did not yield any important effect (Fig. 4).

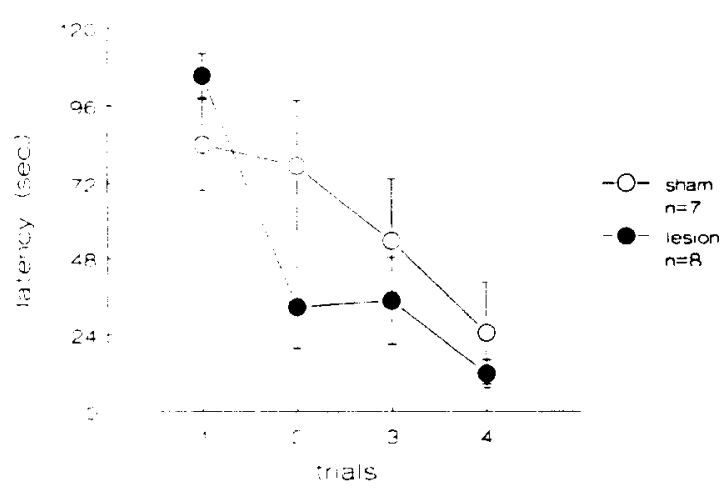

Fig. 3. Morris maze. Mean ( \pm S.E.M.) latency times of the sham-operated and the prelimbic-lesioned rats presented as the four trials after the platform was moved. 


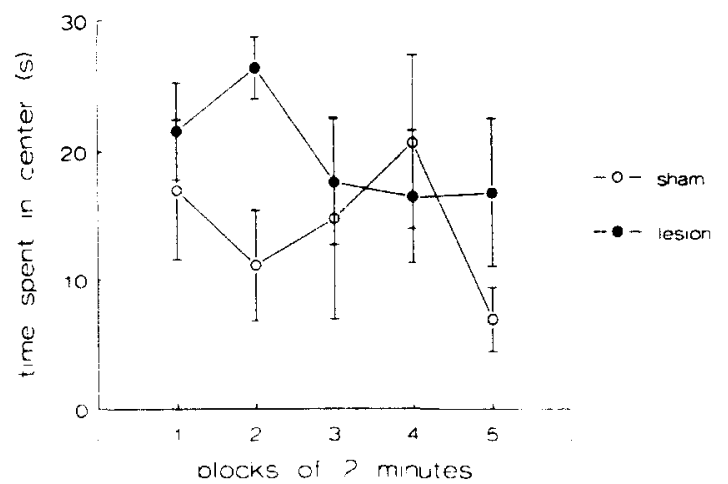

Fig. 4. Open field with object. Mean ( \pm S.E.M.) time spent in the central area (around the object) of the open field. The total duration of $10 \mathrm{~min}$ is divided into 5 blocks of $2 \mathrm{~min}$.

\subsection{Elevated plus-maze}

The results are shown in Fig. 5. The lesioned rats spent more time on the open arms than the shamoperated rats: $F(13,1)=4.528$ and $P<0.053$. There was no difference between groups for the percentage of open arm entries. The total number of entries was significantly higher for the lesioned rats than for the sham-operated rats: $F(13,1)=9.0267$ and $P<0.05$.

\subsection{Shock-prod burying test}

The number of shocks, which was taken as a measure for the prod-shock association, was not different between the groups. The time spent burying (active coping), freezing (passive coping), and exploring (coping irrelevant activity) was also not different between the groups (Fig. 6).

\subsection{Passive avoidance}

The step-through latency during the retention trial was significantly lower in the lesioned rats than the sham-operated rats, with $F(15,1)=6.0555$ and $P<0.05$
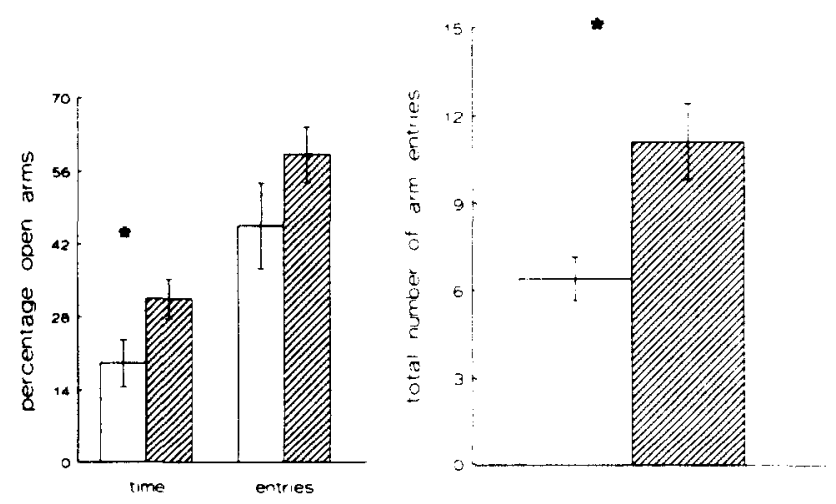

Fig. 5. Elevated plus-maze. Mean ( \pm S.E.M.) percentage of time spent on open arm and of the number of open arm entries (left figure) and total number of arm entries. The blank bars represent the sham-operated animals, the hatched bars the lesioned ones.

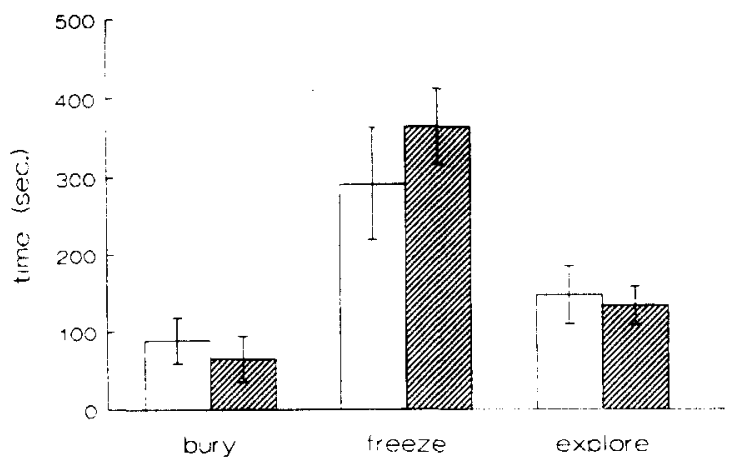

Fig. 6. Shock-prod burying test. Mean ( \pm S.E.M.) time spent burying, freezing, and exploring. The blank bars represent the sham-operated rats and the hatched bars the lesioned rats.

(Fig. 7). There were no differences between the stepthrough latencies of the groups in the habituation and shock trials.

\section{Discussion}

The acquisition of the Morris maze task was not affected by the lesion, but the new position of the platform was learned faster by the lesioned rats than by the sham-operated rats. In the elevated plus-maze, the percentage of open arm entries and the total number of arm entries were higher in the lesioned rats. In the shock-prod burying test there were no differences between the groups when considering the prod-shock association (that is the number of received shocks) and the reactions to the shocks (as measured by time spent on burying, freezing. and exploring). In the open field test, the lesion had no effect on the distance travelled, nor on the time spent in the center. In the step-through passive avoidance task the lesioned rats had a shorter step-through latency time during the retention trial than the sham-operated rats did.

The acquisition of the Morris maze task was not impaired by the lesion. This is in accordance with De

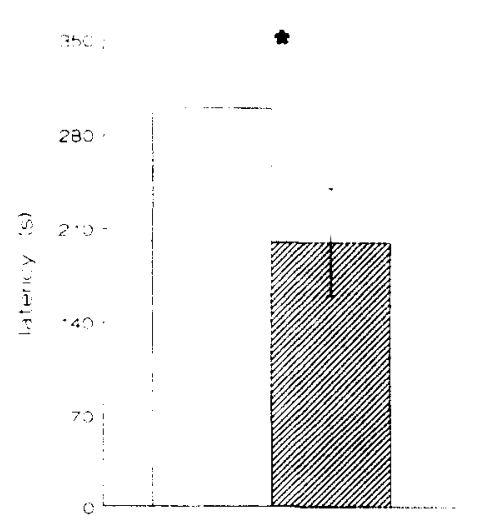

Fig. 7. Passive avoidance. Mean ( \pm S.E.M.) duration until entry into the dark compartment. The blank bar represents the sham-operated rats and the hatched bar the lesioned rats. 
Bruin et al. [10] and in contrast to Kolb et al. [27]. De Bruin et al. [10] have pointed out some differences between the experimental procedures of their own study and those of Kolb et al. [27]. The most important difference is probably that De Bruin et al. [10] (and we) placed the animal on the platform at the end of unsuccessful trials. As they explain, the non-placing on this platform induced in the lesioned animals [27] a scratching at the walls of the pool. A possible interpretation (taking Holsons' timidity hypothesis into account [23-25]) could be an altered emotional reactivity if faced with a failure in escaping. But contrary to De Bruin et al. [10], in our study the lesion improved the performance after reversal (for the possible anxiolytic effect of the lesion see discussion about results in elevated plus-maze). They found an impairment after total lesion of the medial prefrontal cortex, but no effect after lesion of the dorsomedial (area 24) or ventromedial (areas 32 and 25) prefrontal cortex. They suggest this to be the result of a 'mass action', which means that a particular effect is more likely to occur after a large than after a small lesion, obviously assuming that areas 24,32 , and 25 would have the same function. Our results contradict this presumption. The study of Powell et al. [42] points also in the direction of a functional heterogeneity between areas 24,32 and 25 .

In the elevated plus-maze, the lesioned rats spent more time in the open arms and their overall activity (as measured by the total number of arm entries) was higher than that of the sham-operated rats. The percentage of numbers of open arm entries was nearly significant $(P=$ 0.053 ). Since the open arm activity (measured by percentage time spent on these arms and by the percentage of open arm entries) is usually [39] taken as a measure for the anxiolytic effect of a treatment, we may assume that the lesion of the prelimbic area reduces anxiety or anxiety-related responses. This would be opposite to the hypothesis of Holson [23-25], stating an increase of timidity after the lesion. A possible explanation for this is that the lesion in those studies was located more dorsally, including ventral portions of area 24 and only dorsal portions of area 32. There is some indication [22] that the prelimbic area may functionally be subdivided into a dorsal and a ventral part. In our study both parts were damaged. The total number of arm entries was increased by the lesion. which is not seen after administration of anxiolytic drugs [39]. It could indicate altered explorative behavior. Poucet [41] has indeed shown an altered object exploration after medial prefrontal cortex lesion. However. in that case lesioned animals did not react to object displacements (this was also seen in rats with septum lesions). Though both experiments (object exploration and elevated plus-maze) cannot directly be compared, the results could be interpreted as being the opposites of each other as far as exploration is concerned: reduced exploration in the study of Poucet
[41] and increased exploration in our study. As pointed out in the discussion concerning the lesion effects in the reversal task in the Morris maze, the precise extent of the lesion may be responsible for the precise effect (in contrast to the prediction of the 'mass action' hypothesis suggested by De Bruin et al. [10]). The lesion in the study of Poucet [41] affected the medial precentral area, the anterior cingulate area, and the prelimbic area (according to the figure of the lesion in that article only the dorsal part of it). A possible explanation for our results could be motor disinhibition, but this is not consistent with the results obtained for the open field test (see discussion below).

In the open field test the lesioned rats did not travel more than the sham-operated rats, thus there was no sign of motor disinhibition. The overall time spent in the center near the object was not altered by the lesion. There seemed, however, to be a tendency in the prelimbic lesioned rats to approach the object at an earlier stage. During the second block of $2 \mathrm{~min}$, the lesioned rats spent significantly more time in the center than the sham-operated rats did (a $t$-test yielded $P<0.005$ ). However, this can only be taken as an indication for an altered exploration because ANOVA with repeated measurements yielded no group $\times$ time interaction. The test used in this study is different from the one used by Poucet [41] (in which objects were displaced), thus the results are not directly comparable. Nevertheless, one could interpret our findings as an indication for an increased interest in a unfamiliar object, whereas Poucet [41] found that the lesioned animals did not react to the displacement of objects. Thus again a possible contradiction between their and our results, as also pointed out above (discussion about results in elevated plusmaze). Brito and Brito [5] found that the latency of emergence from the home cage into an open field was shortened by a lesion restricted to the prelimbic area, which has some similarity with the apparent shorter latency to object exploration in our study and the shortened latency in finding the platform after reversal in the Morris maze.

None of the parameters of the shock-prod burying test were influenced by the lesion. The number of shocks is probably dependent on the prod-shock association, which is not dependent on an intact septo-hippocampal system, but on an intact basolateral amygdala (Treit et al. [51]). Tests of conditioned reinforcement are not all in the same way dependent of the basolateral amygdala or prelimbic area: conditioned taste aversion is only disrupted by a lesion of the prelimbic area [5], not of the basolateral amygdala [12], whereas in a conditioned reinforcement test with sucrose as primary reinforcer and a tone as secondary reinforcer, only rats with a lesion of the basolateral amygdala were impaired [7]. Whether the primary reinforcer is an appetitive or an aversive stimulus is thus not indicative for the brain 
area involved. However, the sensory modality of the secondary reinforcer is perhaps crucial. The prelimbic area is indeed connected to the nucleus parabrachialis and the nucleus tractus solitarii [50], both of which are involved in processing of taste perception, and may be necessary for the use of gustatory conditioned reinforcers. There is also some indication for the modalityspecific function of the basolateral amygdala [28].

Besides the fact that the prelimbic lesion did not affect the number of shocks received, it did also not have any effect on any other parameter in this test. Treit et al. [51] found a combination of unaltered number of shocks and reduced time spent on burying after a septum lesion, which indicates that response selection was impaired. A possible interpretation of this is that the septohippocampal system is involved in finding the appropriate coping reaction in an aversive situation (see also the theory by Gray [19]). According to D'Angio et al. [9] also the medial prefrontal cortex plays a role in finding the appropriate coping strategy by way of influencing "attentional and/or cognitive processes in an attempt to deal with the stressor". The results of the present study, however, indicate that this is not true for the prelimbic area (it may well be true for the anterior cingulate area), because coping behavior was not influenced by the lesion. However, according to Brito and Brito [5] the prelimbic area is involved in "shifting cognitive strategies in a runway". They inferred this from a task involving tactile discrimination. The question then arises whether sensory modality is important (as it was suggested to be for conditioned reinforcement-see discussion about the results of the shock-prod bury test), which Brito and Brito [5] themselves happen not to believe.

In the step-through passive avoidance task, the lesioned rats performed worse than the sham-operated rats. Since secondary reinforcement was not generally disturbed (prod-shock association in shock-prod burying test) and spatial orientation was not impaired (Morris maze acquisition, this study, see also De Bruin et al. $[10])$, the impact of the lesion on retention in the passive avoidance task could perhaps best be explained by disinhibition of responses. The reduced emergence from the home cage into the open field found by Brito and Brito [5] points in the same direction. although a diminished inhibition to approach the object in the central area of the open field could not (statistically) be demonstrated in this study. Which sort of responses are disinhibited is not clear though. Prelimbic lesion did not result in motor disinhibition in our open field test. The situation-dependency of the lesion on activity was shown by Brito and Brito [5] in comparing the activity in the open field and in the activity box. With fimbria lesioned rats (Maaswinkel et al., submitted) we found the same context-dependent pattern of activity as with prelimbic lesioned rats: elevated activity on elevated plus-maze, but not in the open field. One possible explanation of the impairment after prelimbic lesion could be disruption of short-term memory (only for a specific kind of information, because no disruption in Morris maze test) as shown by Broersen et al. [6]: scopolamine infusion into the prelimbic area resulted in a delay-dependent impairment in a delayed-matching-to-position task (see also disruption of working memory in matching-to-sample and non-matching-to-sample tasks after lesion of the prelimbic area [18]). A problem is that Brito and Brito [5] did not find any effect of the prelimbic lesion in the step-through passive avoidance. The reason for this is not clear, but it should be noted that they also did not find any effect of the septum lesion in this task. Earlier studies in which rats with lesions of the septohippocampal system were tested in the passive avoidance test yielded contrasting results [20]. The precise setting and conditions under which these tests are carried out seem to be critical for the results. This may also be true for the results found for prelimbic lesions. With our experimental procedure we [40] found an impairment in this test with a transection of the fimbria-fornix. Thus our procedure 'works'.

In this study we set out to determine further the sort of response selections the prelimbic area is involved in. After the lesion, it was found that fear responses were reduced in the elevated plus-maze. The tendency to go earlier to the object in the open field could perhaps be explained in the same way. Brito and Brito [5] also found a shortened latency of emergence into the open field. These last two findings (elevated object exploration and quicker emergence) could also be interpreted as altered exploration. This is supported by the elevation of activity in the elevated plus-maze. This increase of activity can, as shown by the activity-box test of Brito and Brito [5] and by our open field test, hardly be explained as motor disinhibition. The impaired retention in the passive avoidance test could be an indication for involvement of some forms of learning. The study of Broersen et al. [6] points in a similar direction. If so, we have to be aware that many other forms of learning are not impaired by the lesion: acquisition in the Morris maze test (this was also found by De Bruin et al. [10]) and shock-prod association. However, conditioned taste aversion was impaired according to the study of Brito and Brito [5], which could be an indication (as explained above) that the prelimbic area is more important for information of some sensory modalities than of others, at least as far as conditioned reinforcement is concerned. The prelimbic area turned out not to be crucial for response selection in the shock-prod burying test. Thus, from our findings it is still not possible to propose a unified functional description of the prelimbic area: timidity is decreased, exploration somehow altered, some particular forms of learning impaired.

An interesting point is that the effects of a lesion limited to the prelimbic area, as they were found in this 
study, are different from those of larger lesions: reduced perseveration (after reversal in the Morris maze task) versus increased perseveration [10], reduced timidity (in the elevated plus-maze) versus increased timidity (in a range of other tasks [23-25,31]), increased exploration (elevated plus-maze, open field) versus decreased exploration (displaced objects [41]). One problem is that the experiments in this study were different from the studies which could be indicative for the opposite effects: for example, we tested timidity in the elevated plus-maze, whereas Holson [23-25] inferred his hypothesis from observations of among other burrowing behavior under different conditions. However, interestingly enough there was not such a clear contrast to the results of studies which investigated lesions or drug-infusions limited to the prelimbic area [5-7].

Much more studies are needed. It will be important to differentiate and compare different lesion sites (the medial prefrontal cortex may not be a functional homogeneous region), to pay more attention to the sensory modalities involved, and to elaborate more thoroughly the psychological or behavioral function to be studied ('exploration' is an example of an overgeneralized term: what for instance is the connection between activity in the elevated plus-maze, reaction to object displacements, latency of emergence into the open field etc.?).

\section{References}

[1] Ader, R., Weyne, J.A. and Moleman, P., Retention of a passive avoidance response as a function of intensity and duration of electric shock, Psychon. Sci., 26 (1972) 125-128.

[2] Barbas, H., Architecture and cortical connections of the prefrontal cortex in the rhesus monkey. In P. Chauvel, A.V. DelgadoEscueta, E. Halgren and J. Bancaud (Eds.). Adrances in Neurology, Vol. 57. Raven Press. New York. 1992.

[3] Berridge, K.C., Fentress. J.C. and Parr, H., Natural syntax rules control action sequence of rats. Behat. Brain Res., 23 (1987) $59-68$.

[4] Bertolucci-D'Angio. M.. Serrano. A.. Driscoll. P. and Scatton. B.. Involvement of mesocorticolimbic dopaminergic systems in emotional states. In H.B.M. Uylings. C.G. van Eden, J.P.C. de Bruin. M.A. Corner and M.G.P. Feenstra (Eds.). The Prefrontal Cortex: Its Structure, Function and Pathologl: Prog. Brain Res., Vol.85. Elsevier, Amsterdam. 1990. pp. 405417

[5] Brito, G.N.O. and Brito, L.S., Septohippocampal system and the prelimbic sector of the frontal cortex: a neuropsychological battery analysis in the rat. Behur. Bruin Re's., 36 (1990) 127-146.

[6] Broersen, L.M.. Heinsbroek, R.P.W.. de Bruin, J.P.C.. Uylings, H.B.M. and Olivier, B., The role of the medial prefrontal cortex in rats in short-term memory functioning: further support for involvement of cholinergic, rather than dopaminergic mechanisms, Brain Res.. 674 (1995) 221229.

[7] Burns, L.H., Robbins, T.W. and Everitt. B.J.. Differential effects of excitotoxic lesions of the basolateral amygdala, ventral subiculum and medial prefrontal cortex on responding with conditioned reinforcement and locomotor activity potentiated by intraaccumbens infusion of D-amphetamine. Behar. Brain Re's. 55 (1993) 167-183.

[8] Condé, F., Maire-Lepoivre. E.. Audinat. E. and Crepel. F.. Affer- ent connections of the medial frontal cortex of the rat, 11 . Cortical and subcortical afferents, J. Comp. Neurol., 352 (1995) 567-593.

[9] D'Angio, M., Serrano, A., Driscoll, P. and Scatton, B., Stressful environmental stimuli increase extracellular DOPAC levels in the prefrontal cortex of hypoemotional (Roman high-avoidance) but not hyperemotional (Roman low-avoidance) rats. An in vivo voltammetric study, Brain Res., 451 (1988) 237-247.

[10] De Bruin, J.P.C., Sanchez-Santed, F., Heinsbroek, R.P.W., Donker, A. and Postmes, P., A behavioural analysis of rats with damage to the medial prefrontal cortex using the morris water maze: evidence for behavioural flexibility, but not for impaired spatial navigation, Brain Res., 652 (1994) 323-333.

[11] Devenport, L.D., Hale, R.L. and Stidham, J.A., Sampling behavior in the radial maze and operant chamber: role of the hippocampus and prefrontal cortex, Behav. Neurosci., 102 (1988) 489-498.

[12] Dunn, A.J. and Everitt, B.J., Double dissociations of the effects of amygdala and insular cortex lesions on conditioned taste aversion, passive avoidance and neophobia in the rat using the excitotoxic ibotenic acid, Behav. Neurosci., 102 (1988) 3-23.

[13] Everitt, B.J. and Robbins, T.W., Amygdala-ventral striatal interactions and reward processes. In J.P. Aggleton (Ed.), The Amygdala: Neurobiological Aspects of Emotion, Memory, and Mental Dysfunction. Wiley-Liss, New York, 1992, pp. 401-430.

[14] Frith, C.D., The Cognitive Neuropsychology of Schizophrenia, Erlbaum, Hillsdale, 1992.

[15] Fuster, J.M., The Prefrontal Cortex, 2nd ed., Raven Press, New York, 1989.

[16] Gabriel, M., Sparenborg, S.P. and Stolar, N., An executive function of the hippocampus: pathway selection for thalamic neuronal significance code. In R.L. Isaacson and K.H. Pribram (Eds.), The Hippocampus, Vol.4, Plenum Press, New York, 1986, pp. 1-39.

[17] Gaffan, D., Amnesia for complex naturalistic scenes and for objects following fornix transection in the Rhesus monkey, Eur. J. Neurosci., 4 (1992) 381-388.

[18] Granon. S., Vidal. C., Thinus-Blanc, C., Changeux, J.P. and Poucet. B., Working memory, response selection, and effortful processing in rats with medial prefrontal lesions, Behav. Neurosci., $108(1994) 883-891$.

[19] Gray, J.A.. The Neuropsychology of Anxiety: An Enquiry into the Functions of the Septo-Hippocampal System, Oxford University Press, New York, 1982.

[20] Gray. J.A. and McNaughton, N., Comparison between the behavioural effects of septal and hippocampal lesions: a review, Neurosci. Biobehar. Ret.. 7 (1983) 119-188.

[21] Groenewegen. H.J.. Organization of the afferent connections of the mediodorsal thalamic nucleus in the rat, related to the mediodorsal-prefrontal topography, Neuroscience, 24 (1988) 379-431.

[22] Groenewegen. H.J., Berendse, H.W., Wolters, J.G. and Lohman, A.H.M. The anatomical relationship of the prefrontal cortex with the striatopallidal system, the thalamus and the amygdala: evidence for a parallel organization. In H.B.M. Uylings, C.G. van Eden. J.P.C. de Bruin. M.A. Corner and M.G.P. Feenstra (Eds.), The Prefrontal Cortex: Its Structure, Function and Pathology, Prog. Brain Res.. Vol. 85, Elsevier, Amsterdam, 1990, pp. 95-118.

[23] Holson. R.R.. Mesial prefrontal cortical lesions and timidity in rats. I. Reactivity to aversive stimuli, Physiol. Behav., 37 (1986) $221-230$.

[24] Holson. R.R.. Mesial prefrontal cortical lesions and timidity in rats, III. Behavior in a semi-natural environment, Physiol. Behav., 37 (1986) 239-247.

[25] Holson, RR. and Walker, C., Mesial prefrontal cortical lesions and timidity in rats, II. Reactivity to novel stimuli, Physiol. Behav., 37 (1986) 231-238.

[26] Kolb, B., Functions of the frontal cortex of the rat: a comparative review, Brain Res. Rev., 8 (1984) 65-98.

[27] Kolb. B.. Sutherland, R.J. and Whishaw, I.Q., A comparison of 
the contributions of the frontal and parietal association cortex to spatial localization in rats. Behav. Neurosci., 97 (1983) 13-27.

[28] Maaswinkel, H., Baars, A.M., Gispen, W.H. and Spruijt, B.M., Roles of the basolateral amygdala and hippocampus in social recognition in rats, Physiol. Behav. (in press).

[29] MacLean, P.D., The Triune Brain in Evolution. Role in Paleocerebral Functions, Plenum Press, New York, 1990.

[30] Mogenson, G.J. and Yang, C.R., The contribution of basal forebrain to limbic-motor integration and the mediation of motivation to action, Adv. Exp. Med. Biol., 295 (1991) 267-290.

[31] Morgan, M.A. and LeDoux, J.E., Differential contribution of dorsal and ventral medial prefrontal cortex to the acquisition and extinction of conditioned fear in rats, Behav. Neurosci., 109 (1995) 681-688.

[32] Morris, R.G.M., An attempt to dissociate 'spatial-mapping' and 'working-memory' theories of hippocampal function. In Seifert (Ed.), Neurobiology of the Hippocampus, Academic Press, London, 1983, pp. 405-432.

[33] Morris, R.G.M., Garrud, P., Rawlins, J.N.P. and O'Keefe, J., Place navigation impaired in rats with hippocampal lesions, Nature (London), 297 (1982) 681-683.

[34] Neafsey, E.J., Prefrontal cortical control of the autonomic nervous systemanatomical and physiological observations. In H.B.M. Uylings, C.G. van Eden, J.P.C. de Bruin, M.A. Corner and M.G.P. Feenstra (Eds.), The Prefrontal Cortex: Its Structure, Function and Pathology, Prog. Brain Res., Vol. 85, Elsevier, Amsterdam, 1990, pp. 147-166.

[35] Neafsey. E.J., Hurley-Gius, K.M. and Arvanitis, D., The topographical organization of neurons in the rat medial frontal, insular and olfactory cortex projecting to the solitary nucleus, olfactory bulb, periaqueductal gray and superior colliculus. Brain Res., 377 (1986) 261-270.

[36] Owen, A.M., Roberts, A.C., Polkey, C.E., Shakian, B.J. and Robbins. T.W., Extra-dimensional versus intra-dimensional set shifting performance following frontal lobe excisions, temporal lobe excisions or amygdalo-hippocampectomy in man, Neuropsychologia, 29 (1991) 993-1006.

[37] Pandya. D.N. and Yeterian, E.H., Prefrontal cortex in relation to other cortical areas in rhesus monkey: architecture and connections. In H.B.M. Uylings, C.G. van Eden, J.P.C. de Bruin. M.A. Corner and M.G.P. Feenstra (Eds.), The Prefrontal Cortex: Its Structure, Function and Pathology, Prog. Brain Res., Vol. 85. Elsevier, Amsterdam, 1991, pp. 63-94.

[38] Paxinos, G. and Watson, C., The Rat Brain in Stereotaxis Coordinates, Academic Press, San Diego, Calif., 1986, 2nd ed.

[39] Pellow, S., Chopin. P.. File, S.E. and Briley, M., Validation of open:closed arm entries in an elevated plus-maze as a measure of anxiety in the rat, J. Neurosci. Methods, 14 (1985) 149-167.

[40] Pitsikas, N., Spruijt, B.M., Josephy, M., Algeri. S. and Gispen W.H., Effect of Org2766, an ACTH(4-9) analogue, on recovery after bilateral transection of the fimbria fornix in the rat. Pharmacol. Biochem. Behav., 38 (1991) 931-934.

[41] Poucet, B., Object exploration, habituation, and response to spatial change in rats following septal and medial frontal cortical damage, Behav. Neurosci., 103 (1989) 1009-1016.

[42] Powell, D.A., Watson, K. and Maxwell, B., Involvement of subdivisions of the medial prefrontal cortex in learned cardiac adjustments in rabbits, Behav. Neurosci., 108 (1994) 294-307.

[43] Preuss, T.M., Do rats have prefrontal cortex? The Rose-WoolseyAkert program reconsidered, J. Cogn. Neurosci. (in press).

[44] Preuss, T.M. and Goldman-Rakic, P.S., Ipsilateral cortical connections of granular frontal cortex in the strepsirhine primate Galago, with comparative comments on anthropoid primates. J. Comp. Neurol., 310 (1991) 507-549.

[45] Room, P.. Russchen, F.T., Groenewegen, H.J. and Lohmann, A.H.M., Efferent connections of the prelimbic (area 32) and the infralimbic (area 25) cortices: an anterograde tracing study in the cat, J. Comp. Neurol., 242 (1985) 40-55.

[46] Sesack. S.R., Deutch, A.Y., Roth, R.H. and Bunney, B.J., Topographical organization of the efferent projections of the medial prefrontal cortex in the rat: an anterograde tract-tracing study with phaseolus vulgaris leucoagglutinin, J. Comp. Neurol.. 290 (1989) 213-242

[47] Spruijt, B.M., Hol, T. and Rousseau, J., Approach, avoidance and contact behavior of individually recognized animals with an imaging technique, Physiol. Behav., 51 (1992) 747-752.

[48] Spruijt. B.M., Josephy, M., Van Rijzingen, I. and Maaswinkel, H., The ACTH(4-9) analog Org2766 modulates the behavioral changes induced by NMDA receptor antagonist AP5, J. Neurosci.. 14 (1994) 3225-3230.

[49] Squire, L.R., Memory and the hippocampus: a synthesis from findings with rats, monkeys, and humans, Psychol. Ret., 99 (1992) 195-231.

[50] Terreberry, R.R. and Neafsey, E.J., Rat medial frontal cortex: a visceral motor region with a direct projection to the solitary nucleus, Brain Res., 278 (1983) 245-249.

[51] Treit, D., Pesold, C. and Rotzinger, S., Dissociating the anti-fear effects of septal and amygdaloid lesions using two pharmacologically validated models of rat anxiety, Behar. Neurosci.. 107 (1993) 770-783.

[52] Worden. R., Navigation by fragment fitting: a theory of hippocampal function. Hippocampus, 2 (1992) 165-187. 